\title{
RANCANG ANGUN MANAJEMEN TRAFIK ROUTING JARINGAN PADA SISTEM INFORMASI PENGELOLAAN KEUANGAN DAERAH KABUPATEN BENGKALIS
}

\author{
Hermansyah $^{1)}$, Dwi Haryono ${ }^{2)}$, Yoyon Efendi ${ }^{3)}$ \\ 1,2,3 Teknik Informatika, STMIK Amik Riau, Jl. Purwodadi Km 10,5 Pekanbaru \\ email: hermansyah@gmail.com, dwiharyono@stmik-amik-riau.ac.id, yoyonefendi@stmik-amik-riau.ac.id
}

\begin{abstract}
Financial Management Information System A system that is very helpful in the management process, at present at the Regional Financial and Asset Management Agency Kab. Bengkalis already has a network system, but there are still some things, especially in the case of less optimal access speed to a server system because there is no management that manages the traffic that direct the serverserver that has been provided. With the development of frameworks that can be help developers build web-based applications, from where came the idea to create "Design Traffic Management Traffic Routing Network In Regional Financial Management Information System Kab. Bengkalis "This application is a traffic management that diverts users to the servers that have been provided for the server to be distributed properly, which will ultimately increase the speed of access from users to the server financial information management system area.
\end{abstract}

Keywords: Web, Regional Financial Management, Networking, Routing.

\begin{abstract}
Abstrak
Sistem Informasi Pengelolaan Keuangan Daerah Merupakan sebuah sistem yang sangat membantu dalam proses pengelolaan keuangan, pada saat ini pada Badan Pengelolaan Keuangan dan Aset Daerah Kab. Bengkalis telah memiliki jaringan sistem tersebut, akan tetapi masih terdapat beberapa kendala, khususnya dalam hal kurang optimalnya kecepatan akses ke sebuah server sistem karena tidak terdapatnya manajemen yang mengelola trafik yang mengarahkan keserver-server yang telah disediakan.Dengan semakin berkembangnya framework-framework yang dapat membantu developer membangun aplikasi berbasis web, dari situlah muncul ide untuk membuat " Rancang Bangun Manajemen Trafik Routing Jaringan Pada Sistem Informasi Pengelolaan Keuangan Daerah Kab. Bengkalis" Aplikasi ini merupakan sebuah manajemen trafik yang mengarahkan user ke server-server tertentu yang telah disediakan agar penggunaan atau pembagian server dapat terdistribusi dengan baik, yang pada akhirnya akan meningkatkan kecepatan akses dari user ke server sistem informasi pengelolaan keuangan daerah.
\end{abstract}

Kata kunci: Web, Manajemen Keuangan Daerah, Jaringan, Routing

\section{PENDAHULUAN}

Perkembangan teknologi jaringan komputer mengalami peningkatan pesat, bersamaan dengan semakin meningkatnya permintaan terkoneksinya lokasi-lokasi yang

terpisah. Dengan perkembangan tersebut, mendorong pertumbuhan jaringan data lokal (Local Area Network) yang tersebar secara geografis bergabung membentuk sistem jaringan yang lebih luas atau jaringan MAN (Metropolitan Area Network) dan diakomodasi oleh routing protokol $(\mathrm{Br}$ Sinaga \& Mubarakah, 2015).

Istilah bandwidth dapat didefinisikan sebagai kapasitas atau daya tampung suatu kanal komunikasi untuk dapat dilewati trafik dalam satuan waktu tertentu. Pengalokasian bandwidth yang tepat dapat menjadi salah satu metode dalam memberikan jaminan kualitas suatu layanan jaringan ( $\mathrm{QoS}=$ Quality Of Services). Sedangkan istilah trafik dapat didefinisikan sebagai banyaknya informasi yang melewati suatu kanal komunikasi(Tengku Ahmad, Sigit Eryzebuan, \& Ali Ahmad, 2010).

Pada Badan Pengelolaan Keuangan dan Aset Daerah Kabupaten Bengkalis, telah lama mengimplementasikan aplikasi SIPKD dalam keperluan penganggaran, pelaksanaan hingga pelaporan keuangan daerah. Diperlukan jaringan yang lebih luas seperti WAN.

WAN merupakan jaringan komputer yang mencakup area yang besar sebagai contoh 
yaitu jaringan komputer antar wilayah, kota atau bahkan negara, atau dapat didefinisikan juga sebagai jaringan komputer yang membutuhkan router dan saluran komunikasi publik. WAN digunakan untuk menghubungkan jaringan area lokal yang satu dengan jaringan lokal yang lain, sehingga pengguna atau komputer di lokasi yang satu dapat berkomunikasi dengan pengguna dan komputer di lokasi yang lain(Dedy Haryanto \& Riadi, 2014)

Agar sistem dapat diakses secara optimal oleh operator-operator yang berada di Satuan Kerja Perangkat Daerah (SKPD) dan seluruh Kecamatan yang ada di Kabupaten Bengkalis, BPKAD telah membangun jaringan komputer yang terhubung baik melalui Wide Area Network (WAN) BPKAD maupun akses melalui internet untuk SOPD dan Kecamatan yang jauh dari kantor BPKAD Kab. Bengkalis, selain itu agar lalu lintas data dari operatoroperator di SKPD menuju ke server sistem dapat terbagi sekaligus untuk meringankan beban server utama, telah disediakan beberapa server alternatif yang dapat diakses.

Sayangnya, penambahan beberapa server tidak serta merta membuat akses ke server menjadi lebih optimal, karena ada beberapa hal yang menjadi persoalan, antara lain, pada sistem yang sedang berjalan, pemilihan server masih dilakukan secara manual oleh operator di SKPD pada saat mereka mengakses sistem, sehingga kebanyakan operator akan terus mengakses server yang sama setiap kali sistem dijalankan, hal ini disebabkan kebanyakan operator tidak mau mengubah alamat atau $u r l$ sistem pada addressbarbrowser.

Selain itu, karena Sistem Informasi Pengelolaan Keuangan Daerah ini berbasis framework Microsoft, ada beberapa systemrequirement yang harus dipenuhi, yaitu harus menggunakan browser Microsoft Internet Explorer dan ada beberapa pengaturan pada Compatibility Views Setting setiap kali user merubah atau mengarahkan browser ke alamat server yang baru. Karena kerumitan pengaturan inilah yang membuat sebagian operator enggan melakukan perubahan alamat server.

\section{LANDASAN TEORI}

Pengendalian Trafik Jaringan
Trafik jaringan berhubungan dengan paket data yang dibangkitkan oleh kartu ethernet pada komputer (Santosa, 2004). Paket data yang dikirimkan oleh komputer lain diterima NIC (kartu ethernet).

Menurutnya lagi, dalam mengendalikan trafik administrator jaringan bisa memilih beberapa metode tergantung dari situasi pada jaringan LAN atau Backbone. Tiap trafik akan dikendalikan dengan metode tertentu yang akan berdampak pada kecepatan akses, jadi administrator jaringan perlu membaca dan mengerti bagian ini terlebih dahulu, beberapa metode pengendalian trafik sebagai berikut :

\section{Prioritas}

Pada metode prioritas paket data yang melintasi gateway diberikan prioritas berdasarkan port, alamat IP atau subnet. Jika trafik pada gateway sedang tinggi maka prioritas dengan nilai terendah (nilai paling rendah berarti prioritas tertinggi) akan diproses terlebih dahulu, sedangkan yang lainnya akan di berikan ke antrian atau dibuang. Metode prioritas paling cocok diterapkan pada koneksi internet yang memiliki bandwidth sempit, hanya trafik paling penting saja yang dilewatkan seperti smtp dan pop3, seperti yang terlihat pada Gambar 1 dibawah ini :

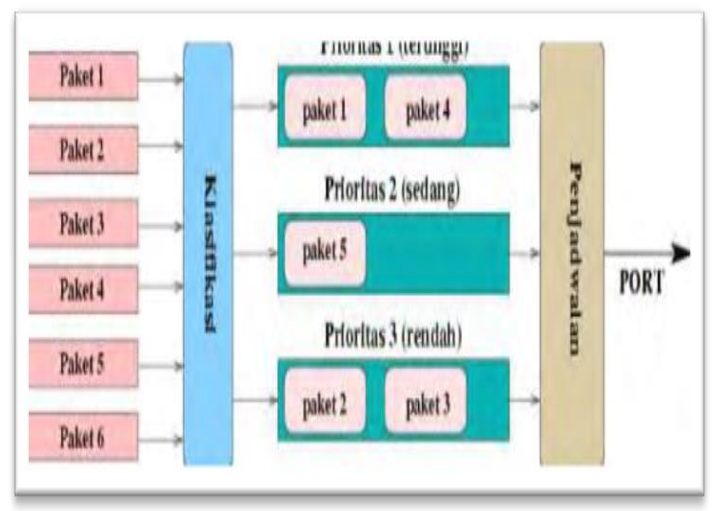

Gambar 1 Metode Prioritas

\section{2. $\quad$ First In First Out (FIFO)}

Pada metode FIFO jika trafik melebihi nilai set maka paket data akan dimasukkan ke antrian, paket data tidak mengalami pembuangan hanya tertunda beberapa saat. Metode FIFO cocok diterapkan pada koneksi internet dengan bandwidth menengah 64 kbps, untuk menghindari bootleneck pada jaringan LAN. Paket data jika melebihi batas konfigurasi akan di masukkan ke dalam antrian dan pada saat jaringan LAN 
tidak sibuk maka paket data dalam antrian akan dikeluarkan. Dapat dilihat pada gambar 2 sebagai berikut:

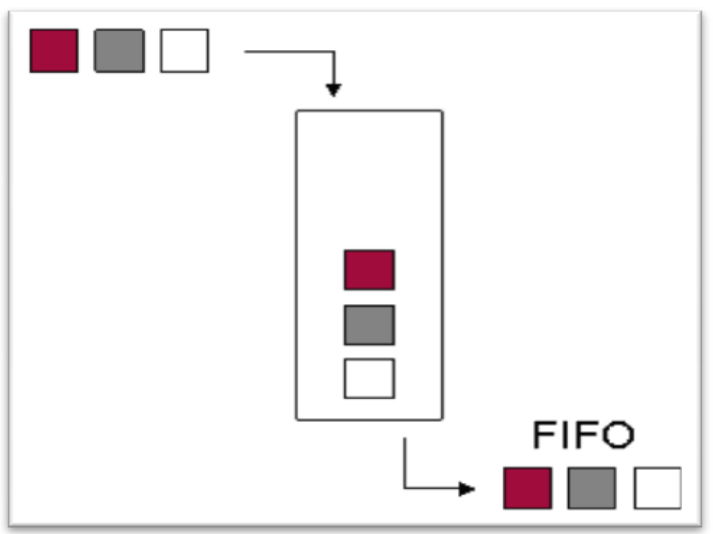

Gambar 1. First In First Out

\section{Penjadwalan}

Metode penjadwalan atau scheduling ini paling sering dipakai karena memiliki kemampuan membagi paket data ke dalam ukuran yang sama besar kemudian memasukkan ke dalam beberapa antrian. Antrian itu kemudian di keluarkan oleh scheduler dengan algoritma roundrobin. Konsep metode penjadawlan dapat dilihat pada gambar 3 dibawah ini :

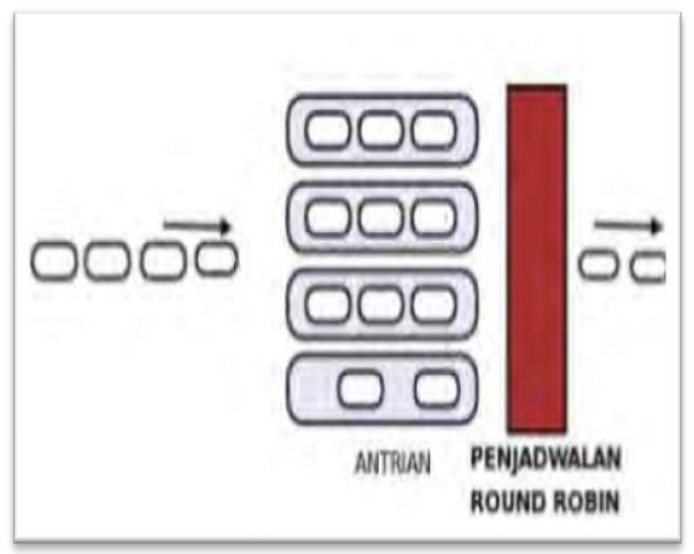

Gambar 2. Penjadwalan

\section{Shape \& Drop}

Shape \& drop merupakan metode paling cocok serta efektif untuk jaringan yang memiliki beban trafik sangat tinggi. Jika trafik melebihi nilai set maka paket data akan di masukan ke dalam antrian sehingga trafik menurun secara perlahan, metode ini disebut pemotongan bandwidth, kemudian jika trafik terus menerus melebihi nilai set maka paket data akan dibuang (drop). Dapat dilihat pada gambar 4 sebagai berikut:
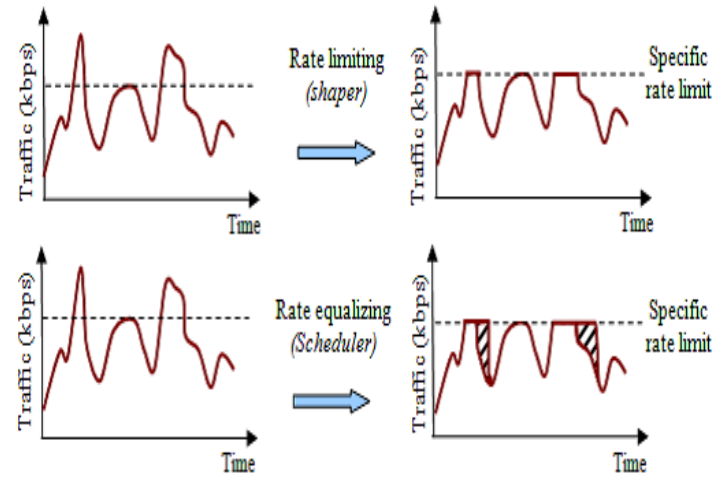

Gambar 4. Shape and Drop

\section{Routing}

Router adalah alat jaringan komputer yang mengirimkan paket data melalui sebuah jaringan atau internet menuju tujuannya, melalui sebuah yang dikenal sebagai routing.

Routing adalah proses menentukan rute dari host asal ke host tujuan. Routing merupakan proses memindahkan data dari satu network ke network lain dengan cara memforward paket data via gateway. Routing menentukan kemana datagram akan dikirim agar mencapai tujuan yang diinginkan Informasi yang dibutuhkan router dalam melakukan routing yaitu:

1. Alamat tujuan/ destination address.

2. Mengenal sumber informasi.

3. Menemukan rute.

4. Pemilihan rute

5. Menjaga informasi routing(Jati, Nurwasito, \& Data, 2018).

Pada suatu sistem jaringan komputer, router mempelajari informasi routing dari sumber-sumber routing-nya yang terletak di dalam tabel routing (routing table). Router akan berpedoman pada tabel ini untuk menyatakan port mana yang digunakan memforward paket-paket yang ditujukan kepadanya.

1. Jika jaringan tujuan terhubung langsung dengan router, maka router sudah mengetahui port mana yang digunakan untuk mem-forward paket.

2. Jika jaringan tujuan tidak terhubung langsung dengan router, maka router harus mempelajari rute terbaik untuk mem-forward paket ke tujuan(Edi, 2006).

Dalam berkomunikasi data di butuhkan pencarian jalan tercepat yang di namakan routing, untuk mengefisienkan waktu agar 
packet packet data yang di kirimkan dapat di terima secepat mungkin. Routing protocol ada beberapa jenis dari perbedaan jenis yaitu routing statis dan routing dinamis(Santoso, 1945)

1. Static Routing :

Rute harus dimasukan secara manual oleh networkadministrator ke dalam Routing Table. Konsep implementasi Static Routing dapat dilihat seperti gambar dibawah ini:

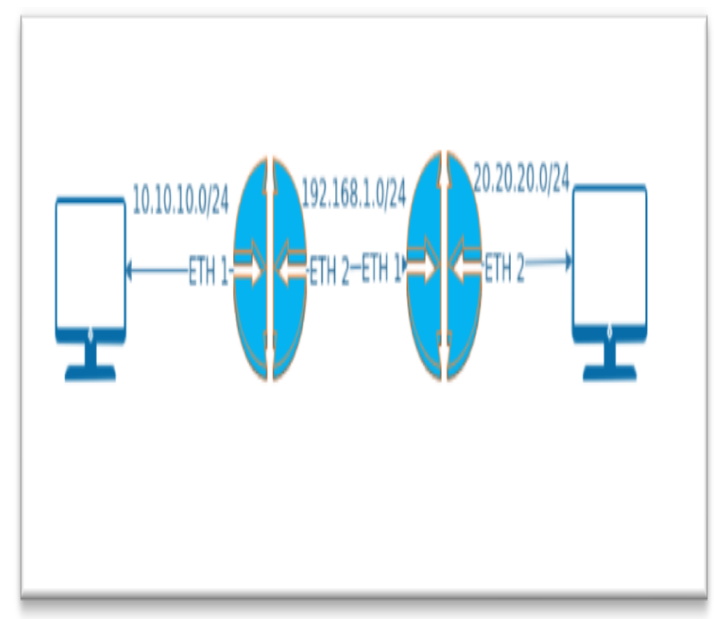

Gambar 5. Konsep Static Routing

2. Dynamic Routing :

sebuah protokol yang berjalan pada router akan berkomunikasi dengan router tetangga yang menjalankan protokol yang sama.

\section{METODE PENELITIAN}

\subsection{Analisa dan Perancangan Sistem}

\section{Analisa Perangkat Lunak}

Untuk memperoleh gambaran yang jelas tentang berbagai hal yang berkaitan dengan perancangan sistem yang akan dibangun, maka perlu dilakukan analisa perangkat lunak.

1. Sistem informasi nantinya berbasis web, menggunakan alat bantu aplikasi desktop yaitu Internet Explorer.

2. Agar sistem ini nantinya berjalan dengan baik dan sesuai dengan fungsinya, sistem ini akan dibangun menggunakan frameworkDrupal dengan basis bahasa pemerograman PHP sebagai penempatan sistem dan HTML untuk mendukung Template (Tampilan).

\section{Analisa Sistem yang Berjalan}

Pada sistem yang sedang berjalan, pemilihan server saat mengakses Sistem Informasi Pengelolaan Keuangan Daerah dilakukan secara manual yaitu dengan cara mengetikkan alamat IP server yang dipilih pada address bar browserInternetExplorer.

\section{Analisa dan Kebutuhan Fungsional}

Analisa kebutuhan fungsional menggambarkan proses kegiatan yang akan diterapkan dalam sebuah sistem dan menjelaskan kebutuhan yang diperlukan sistem agar sistem dapat berjalan dengan baik serta sesuai dengan kebutuhan.

\section{Spesifikasi Sistem}

Adapun spesifikasi sistem yang dibutuhkan dalam pembuatan aplikasi ini antara lain :

1. Aplikasi dibangun dengan menggunakan bahasa pemrograman PHP dan HTML

2. Aplikasi yang dibangun menggunakan media editor dalam pemrograman HTML dan PHP yaitu dengan text editor Atom.

3. Penyimpanan data pengolahan pada aplikasi ini menggunakan Database Server MYSQL dan AcquiaDev Desktop sebagai aplikasi Web Server.

4. Aplikasi ini dapat dibuka dengan menggunakan browser pada Internet Explorer.

\section{Analisa dan Kebutuhan Non-Fungsional}

Analisa kebutuhan non fungsional menggambarkan kebutuhan sistem yang menitikberatkan pada properti perilaku yang dimiliki oleh sistem, diantaranya kebutuhan perangkat keras, perangkat lunak, serta usersebagai bahan analisis kekurangan dan kebutuhan yang harus dipenuhi dalam perancangan sistem yang akan diterapkan.

\subsection{Analisa Metode Static Routing}

Static routing adalah metode routing yang tabel jaringannya dibuat secara manual oleh administrator jaringannya. Staticrouting mengharuskan admin untuk merubahroute atau memasukkan command secara manual di router tiap kali terjadi perubahan jalur. Router meneruskan paket dari sebuah network ke network yang lainnya berdasarkan rute(catatan: seperti rute pada bis kota) yang ditentukan oleh administrator. Rute pada staticrouting tidak berubah, kecuali jika diubah secara manual oleh administrator.

Adapun static routing yang akan diimplementasikan pada sistem yang akan 
dibangun adalah berdasarkan hak akses user yang dikelompokkan kedalam 4 kelompok, yaitu :
1. Operator SKPD
2. Operator lokal
3. Operator Internet
4. Admin

\section{Kebutuhan Perangkat Keras}

Perangkat lunak memberikan instruksi-instruksi kepada perangkat keras untuk melakukan tugas tertentu. Perangkat keras yang digunakan untuk membangun aplikasi adalah sebagai berikut.

Tabel 1. Tabel Perangkat Keras

\begin{tabular}{|l|l|}
\hline \multicolumn{1}{l|}{$($ Hardware $)$} \\
\hline Processor & Intel core i5, 2.4Ghz \\
\hline RAM & DDR34GB \\
\hline Harddisk & $120 \mathrm{~GB}$ \\
\hline VGA & Intel Iris 1536MB \\
\hline
\end{tabular}

\section{Kebutuhan Perangkat Lunak}

Berikut ini adalah spesifikasi minimum perangkat lunak (Software)yang digunakan dalam membangun aplikasi ini :

Tabel 2. Tabel Perangkat Lunak (Software)

\begin{tabular}{|l|l|}
\hline Operation Sistem & MacOS Sierra \\
\hline Editor & Atom Text editor \\
\hline Server Web & AcquiaDev Desktop \\
\hline Browser & $\begin{array}{l}\text { Web Browser } \\
\text { (Mozillafirefox 11.0). }\end{array}$ \\
\hline
\end{tabular}

\section{Spesifikasi Server Manajemen Routing dan Server SIPKD}

Untuk mendukung proses manajemen trafik dan pengelolaan keuangan yang lancar, telah didukung oleh beberapa server yang memiliki spesifikasi yang cukup, sebagaimana yang ditampilkan pada gambar 6 dibawah ini:
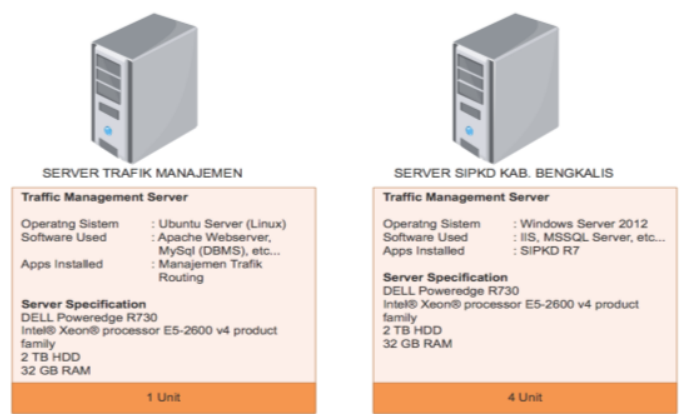

Gambar 6. Spesifikasi Server

\section{Kebutuhan User (Pengguna)}

Pada aplikasi web ini terdapat 4 jenis pengguna yang akan mengoperasikan sistem, yaitu Operator SKPD, Operator lokal, Operator Internetdan admin.

1. Operator SKPD adalah operator yang terhubung melalui jaringan WAN BPKAD yang berada di Kota Bengkalis dan sekitarnya, yang diarahkan ke server dengan alamat IP Lokal.

2. Operator lokal adalah karyawan BPKAD yang mengakses Sistem Informasi berada di kantor BPKAD.

3. Operator Internet adalah operator yang mengakses sistem informasi melalui koneksi internet, operator ini akan di routing ke server-server yang memiliki IP publik.

4. Admin memiliki hak untuk mengakses seluruh Server, selain itu admin juga dapat mengakses backend sistem operasi untuk melakukan pengaturan terkait pengaturan user operator, penambahan atau penggantian server dan lain-lain.

\section{Spesifikasi User}

Aplikasi ini dapat diakses pada PC dan laptop, aplikasi ini juga bisa diakses oleh banyakuser. Secara umum alur sistem aplikasi yang dibuat adalah sebagai berikut :

1. User dapat melakukan loginterlebih dahulu jika sudah memiliki usernamedanpasswordbisa langsung loginke sistem namun jika tidak maka harus melakukan pendaftaran ke sistem.

2. Setelah usermelakukan login maka akan tampil interface untuk mengakses server sesuai dengan hak akses yang diberikan.

3. Jika user adalah Admin, akan tampil piihan semua server dan menu tambahan untuk manajemen sistem. 
Langkah-langkah tersebut dapat digambarkan ke dalam sebuah flowchart sistem dibawah ini:

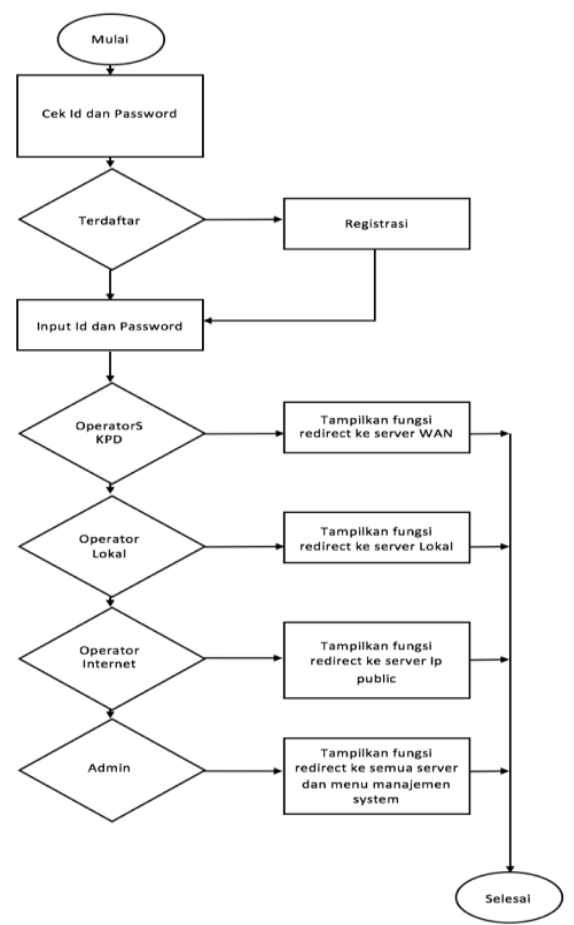

Gambar 7. Flowchart Sistem Manajemen Trafik

\section{HASIL DAN PEMBAHASAN}

\subsection{Implementasi Sistem}

Implementasi system merupakan tahap penerapan dan sekaligus pengujian terhadap system berdasarkan hasil analisa dan perancangan yang telah dilakukan. Implementasi sistem yang dibuat berbasis web, dimana file-file sistem yang dibuat diletakkan di server web online, system cukup dikonfigurasi di server. Berdasarkan implementasi system diatas terdapat interface (antarmuka) login sistem yang diakses oleh user (pengguna) dan admin sebagai berikut :

\subsubsection{Tampilan Menu Login}

Menu login ini terdiri dari 2 level, yaitu level admin dan level user, level admin memiliki hak akses untuk menambah, mengubah, dan menghapus data Server.Sedangkan level user hanya bisa melihat mengakses menu server routing. Gambaran halaman login dapat dilihat pada gambar 8

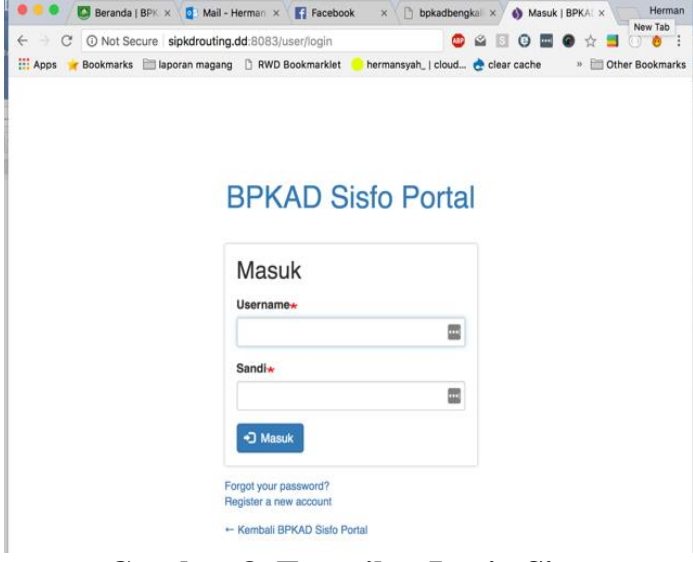

Gambar 8. Tampilan Login Sistem

\subsubsection{Tampilan Halaman Utama}

Halaman Utama merupakan tampilan awal setelah melakukan login. Tampilan halaman utama ini dibedakan berdasarkan level pengguna. Tampilan halaman utama dapat dilihat pada gambar 9

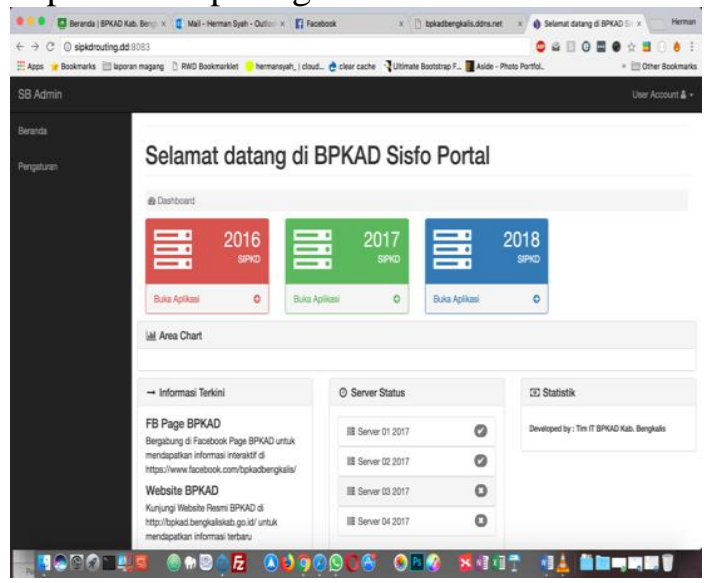

Gambar 9. Tampilah Halaman Utama

\subsubsection{Menu Administrator}

Menu administrator adalah menu untuk melakukan penginputan, menambah, mengubah, dan menghapus keseluruhan data yang dapat dilihat pada Gambar 10

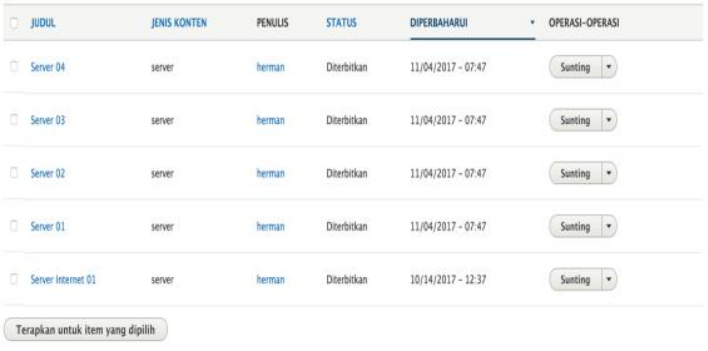

Gambar 10. Menu Administrator 


\subsubsection{Form Tambah Data Server}

Form tambah data admin merupakan sebuah form yang berada pada menu utama. Pada form data admin terdapat form tambah data admin yang merupakan sebuah form untuk melakukan penginputan data admin yang baru. Tampilan input tambah data yang dapat dilihat seperti pada gambar 11 .

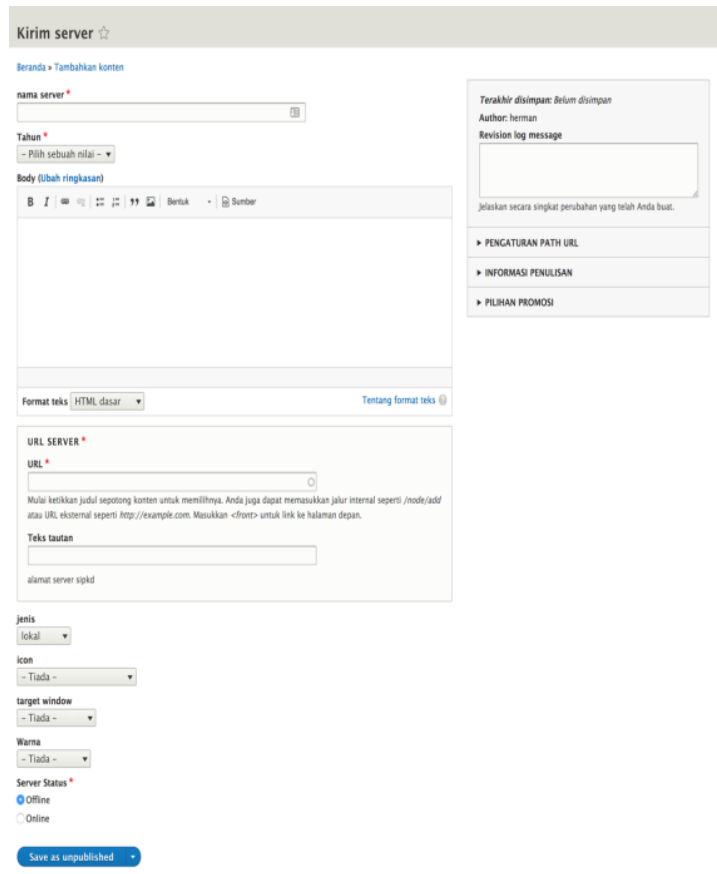

Gambar 11. Form tambah data server

\subsubsection{Pengelolaan Data User}

Fitur ini berfungsi sebagai membuat, mengedit atau menghapus data user. Tampilan pengelolaan data user dapat dilihat pada gambar 12.

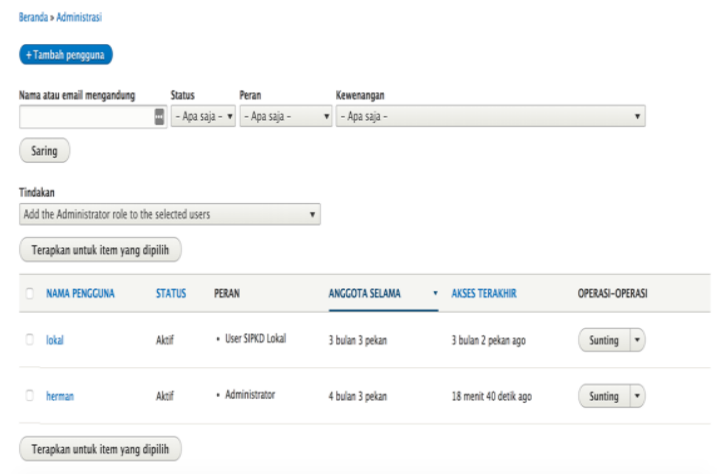

Gambar 12. Pengelolaan datauser

\subsubsection{Halaman Routing Server SIPKD untuk user}

Halaman utama user terdapat beberapa menu yang mengarahkan ke masing-masing aplikasi, seperti yang ditampilkan pada Gambar 13 berikut ini:

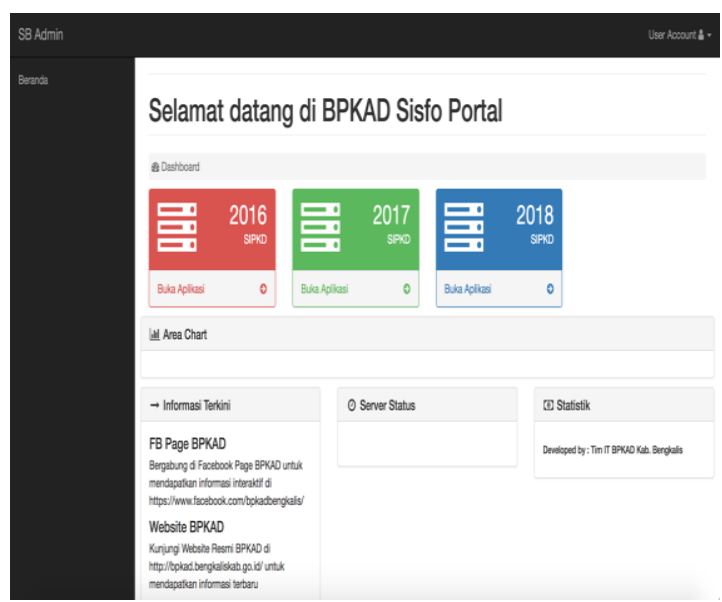

Gambar 13. Halaman routing untuk user

\subsubsection{Halaman Routing Aplikasi SIPKD untuk admin}

Halaman utama Administrator hamper sama dengan halaman user biasa, perbedaannya terletak pada terdapat menu shortcut untuk melakukan pengaturan dan terdapat link keseluruh server yang ada dengan tujuan melakukan ujicoba seluruh server.

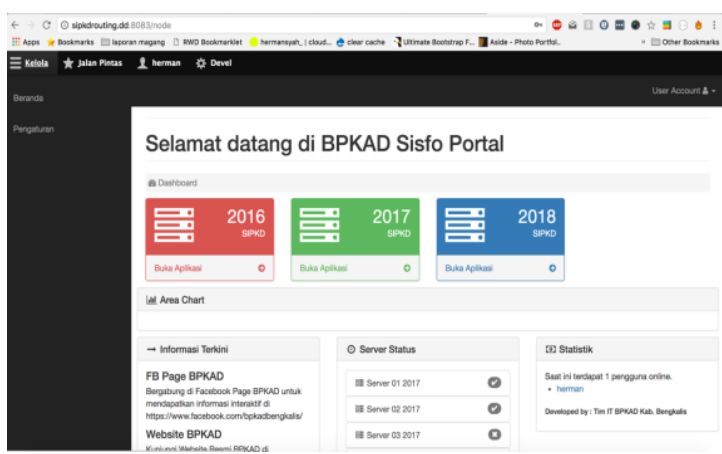

Gambar 14. Halaman routing untuk admin

\subsection{Pengujian \\ 3.2.1 Pengujian Sistem}

Pengujian yang dilakukan pada Sistem Manajemen Trafik Routing Jaringan Sistem Informasi Pengelolaan Keuangan Daerah Kabupaten Bengkalis ini adalah sebagai berikut: 
Tabel 3. Tabel Pengujian

\begin{tabular}{|c|c|}
\hline Entitas yang diuji & ButirUji \\
\hline Login sebagai User & Masukdimenuutama \\
\hline $\begin{array}{ll}\text { Login } & \text { sebagai } \\
\text { Administrator }\end{array}$ & Masukdimenuutama \\
\hline
\end{tabular}

\subsubsection{Hasil Pengujian}

Untuk pengujian pertama, id login yang digunakan adalah user dengan hak akses user, dilakukan sebanyak sepuluh kali dengan hasil sebagaimana yang tertera pada tabel IV.2 berikut ini :

Tabel 4. Tabel uji user

\begin{tabular}{|l|l|l|l|l|}
\hline No & Pengujian & Hasil & Ket & $\begin{array}{c}\text { Sesuai / } \\
\text { Tidak }\end{array}$ \\
\hline 1 & Pengujian 1 & Server 01 & & Sesuai \\
\hline 2 & Pengujian 2 & Server 01 & & Sesuai \\
\hline 3 & Pengujian 3 & Server 02 & & Sesuai \\
\hline 4 & Pengujian 4 & Server 01 & & Sesuai \\
\hline 5 & Pengujian 5 & Server 02 & & Sesuai \\
\hline 6 & Pengujian 6 & Server 02 & & Sesuai \\
\hline 7 & Pengujian 7 & Server 01 & & Sesuai \\
\hline 8 & Pengujian 8 & Server 02 & & Sesuai \\
\hline 9 & Pengujian 9 & Server 01 & & Sesuai \\
\hline 10 & Pengujian 10 & Server 02 & & Sesuai \\
\hline
\end{tabular}

Untuk pengujian kedua, id login yang digunakan adalah user dengan hak akses administrator, dilakukan sebanyak sepuluh kali dengan hasil sebagaimana yang tertera pada tabel 2.3 berikut ini :

Tabel 5. Tabel uji admin

\begin{tabular}{|c|c|c|c|c|}
\hline No & Pengujian & Hasil & Keterangan & $\begin{array}{c}\text { Sesuai } \\
/ \\
\text { Tidak }\end{array}$ \\
\hline 1 & $\begin{array}{c}\text { Pengujian } \\
1 \\
\end{array}$ & $\begin{array}{c}\text { Server } \\
01 \\
\end{array}$ & $\begin{array}{l}\text { tampil menu } \\
\text { admin }\end{array}$ & Sesuai \\
\hline 2 & $\begin{array}{c}\text { Pengujian } \\
2\end{array}$ & $\begin{array}{c}\text { Server } \\
04\end{array}$ & $\begin{array}{l}\text { tampil menu } \\
\text { admin }\end{array}$ & Sesuai \\
\hline 3 & $\begin{array}{c}\text { Pengujian } \\
3\end{array}$ & $\begin{array}{c}\text { Server } \\
03\end{array}$ & $\begin{array}{l}\text { tampil menu } \\
\text { admin }\end{array}$ & Sesuai \\
\hline 4 & $\begin{array}{c}\text { Pengujian } \\
4\end{array}$ & $\begin{array}{c}\text { Server } \\
04\end{array}$ & $\begin{array}{l}\text { tampil menu } \\
\text { admin }\end{array}$ & Sesuai \\
\hline 5 & $\begin{array}{c}\text { Pengujian } \\
5 \\
\end{array}$ & $\begin{array}{c}\text { Server } \\
01 \\
\end{array}$ & $\begin{array}{l}\text { tampil menu } \\
\text { admin }\end{array}$ & Sesuai \\
\hline 6 & $\begin{array}{c}\text { Pengujian } \\
6\end{array}$ & $\begin{array}{c}\text { Server } \\
02 \\
\end{array}$ & $\begin{array}{l}\text { tampil menu } \\
\text { admin }\end{array}$ & Sesuai \\
\hline 7 & $\begin{array}{c}\text { Pengujian } \\
7\end{array}$ & $\begin{array}{c}\text { Server } \\
01\end{array}$ & $\begin{array}{l}\text { tampil menu } \\
\text { admin }\end{array}$ & Sesuai \\
\hline 8 & $\begin{array}{c}\text { Pengujian } \\
8\end{array}$ & $\begin{array}{c}\text { Server } \\
04\end{array}$ & $\begin{array}{l}\text { tampil menu } \\
\text { admin }\end{array}$ & Sesuai \\
\hline 9 & $\begin{array}{c}\text { Pengujian } \\
9 \\
\end{array}$ & $\begin{array}{c}\text { Server } \\
03 \\
\end{array}$ & $\begin{array}{l}\text { tampil menu } \\
\text { admin }\end{array}$ & Sesuai \\
\hline 10 & $\begin{array}{c}\text { Pengujian } \\
10\end{array}$ & $\begin{array}{c}\text { Server } \\
02\end{array}$ & $\begin{array}{l}\text { tampil menu } \\
\text { admin }\end{array}$ & Sesuai \\
\hline
\end{tabular}

\section{SIMPULAN}

Berdasarkan hasil analisa dan pembahasan serta uraian sebelumnya maka kesimpulan dari penelitian ini adalah :

1. Rancangan manajemen trafik routing jaringan ini membantu operator dan admin dalam melakukan optimalisasi pengelolaan keuangan daerah .

2. Rancangan menajemen trafik routing ini dapat menentukan server yang diakses oleh user atau operator tertentu berdasarkan hak akses yang diberikan oleh admin.

\section{UCAPAN TERIMAKASIH}

Ucapan terimakasih kepada STMIK Amik Riau, Dinas Pendapatan Daerah Kabupaten Bengkalis dan semua pihak yang telah membantu atas bantuan melakukan penelitian ini.

\section{DAFTAR PUSTAKA}

Br Sinaga, D., \& Mubarakah, N. (2015). Analisis Kinerja Enhanced Interior Gateway Routing Protocol Pada Topologi Mesh, (1), 72-76.

Dedy Haryanto, M., \& Riadi, I. (2014). ANALISIS DAN OPTIMALISASI JARINGAN MENGGUNAKAN TEKNIK LOAD BALANCING (Studi Kasus: Jaringan UAD Kampus 3). Jurnal Sarjana Teknik Informatika, 2(2), 2338-5197.

Edi, D. (2006). Kajian Algoritma Routing dalam Jaringan Komputer. Jurnal Informatika UKM, II(65), 47-55.

Jati, W. S., Nurwasito, H., \& Data, M. (2018). Perbandingan Kinerja Protocol Routing Open Shortest Path First ( OSPF ) dan Routing Information Protocol ( RIP ) Menggunakan Simulator Cisco Packet Tracer, 2(8), 24422448.

Santoso, K. A. (1945). Konfigurasi dan Analisis Performansi Routing OSPF pada Jaringan LAN dengan Simulator Cisco Packet Tracer versi $6.2,1(1), 67-78$.

Tengku Ahmad, R., Sigit Eryzebuan, Y., \& Ali Ahmad, U. (2010). Implementasi Manajemen Trafik dan Bandwidth Internet dengan IPCop. Junrnal INKOM, IV(1), 28. 